Bull. Chem. Soc. Ethiop. 2019, 33(1), 159-168.

ISSN 1011-3924

(c) 2019 Chemical Society of Ethiopia and The Authors

Printed in Ethiopia

DOI: https://dx.doi.org/10.4314/bcse.v33i1.16

\title{
AN INVESTIGATION ON MITIGATION OF CORROSION OF MILDSTEEL BY ORIGANUM VULGARE IN ACIDIC MEDIUM
}

\author{
Pooja Dhaundiyal, Sumayah Bashir, Vivek Sharma and Ashish Kumar* \\ Department of Chemistry, School of Physical Sciences, Lovely Professional University, \\ Punjab-144401, India
}

(Received February 21, 2018; Revised October 23, 2018; Accepted November 16, 2018)

\begin{abstract}
The restraining impact of plant extract towards corrosion of mild steel has been reviewed in this paper. The purpose of the present investigation is the utilization of Origanum vulgare (oregano) extract as environment friendly corrosion inhibitor of mild steel in $\mathrm{HCl}$ medium. Methods include weight loss, quantum chemical calculations and SEM. The outcomes revealed that the efficiency of Origanum vulgare increased with increasing its concentration reaching maximum of $91.2 \%$ at $1000 \mathrm{mg} / \mathrm{L}$ at $30^{\circ} \mathrm{C}$. Results showed that adsorption followed Langmuir adsorption isotherm. The adsorption attributes of chosen extract were hypothetically assessed by quantum chemical and the morphology of metal was studied by using SEM analysis.
\end{abstract}

KEY WORDS: Mild steel, Origanum vulgare, Corrosion inhibitor, $\mathrm{HCl}$, Corrosion inhibition, Weight loss

\section{INTRODUCTION}

Corrosion forms are responsible for various misfortunes, fundamentally with regards to industry. Corrosion is a steady and constant issue; it is often hard to dispose of it totally. Because of the brilliant mechanical properties and minimal effort, mild steel is broadly utilized as a constructional material in numerous businesses. Mild steel is a composite type of iron, which experiences corrosion effortlessly in acidic medium. Acidic solutions are widely utilized as a part of substance research facilities and in a few mechanical procedures, for example, corrosive pickling, corrosive cleaning, corrosive descaling and oil wet cleaning [1-5]. One of the most effective corrosion inhibitors of metals are organic compounds. The adsorption of these inhibitors is due to compound containing heteroatom, for example, nitrogen, oxygen and sulfur. These compounds which are adsorbed on the metallic surface may hinder the active sites of corrosion [6-8]. Despite the fact that numerous synthetic organic compounds showed good anticorrosive activity, most of them are lethal to both people and nature. Due to the ecological necessities for eco-friendly corrosion inhibitors, there is a growing interest in the use of natural products such as leaves or seeds extracts. It has been found that Origanum vulgare is a good inhibitor for aluminum corrosion but mild steel corrosion inhibition by Origanum vulgare has not been investigated [9-11].

Considerable studies are being done to focus on the search of eco-friendly corrosion inhibitors. According to literature a lot of work has been done to study plant extracts as effective corrosion inhibitors [12]. Besides being cheap the plant extracts are non toxic and environment friendly. Some of the eco-friendly plant extracts used as steel corrosion inhibitors includes Gossipium hirsutum L. [13], mentha [14], mustard [15], Artemisia [16], Dianilis [17], Berberine [18], and Sichuan pepper [19]. We spotted that these extracts have shown excellent corrosion inhibition of mild steel [20]. It was seen that corrosion inhibition varied generally with immersion time, temperature and concentration of inhibitor.

In the present work, an attempt has been made to explore the possibility of oregano as corrosion inhibitor of mild steel in acidic medium. The active constituents of oregano

*Corresponding author. E-mail: drashishchemlpu@gmail.com

This work is licensed under the Creative Commons Attribution 4.0 International License 
(Origanum vulgare) include thymol and carvacrol. As seen from the molecular structures, these constituents contain heteroatom (oxygen) which can prove to be very effective for the corrosion inhibition. The molecular structures of thymol and carvacrol can be shown as below:

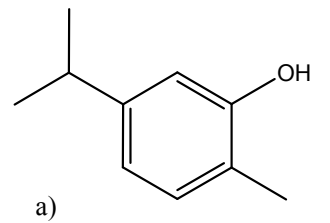

Carvacrol

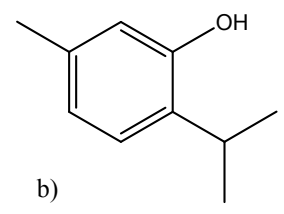

Thymol

Figure 1. Active constituents of oregano (Origanum vulgare).

\section{EXPERIMENTAL}

\section{Materials and material preparation}

Dried oregano plant leaves were refluxed for $5 \mathrm{~h}$ which were soaked in deionized water. After refluxing, aqueous solution was filtered and concentrated to $100 \mathrm{~mL}$. The desired inhibitor concentrations $(400 \mathrm{mg} / \mathrm{L}$ to $1200 \mathrm{mg} / \mathrm{L})$ were obtained by adding calculated amount of plant extract to standard $\mathrm{HCl}$ solution [18]. The corrosive medium $(1,2,3,4$ and $5 \mathrm{M})$ was prepared by using $35 \% \mathrm{HCl}$ from Rankem chemicals with distilled water.

\section{Weight loss method}

The specimen of mild steel used for the weight loss studies was composed of Fe $(99.30 \%), \mathrm{C}$ $(0.076 \%), \mathrm{Si}(0.026 \%), \mathrm{Mn}(0.192 \%), \mathrm{Cr}(0.050 \%)$ and $\mathrm{Ni}(0.050 \%)$. The coupons of this specimen were cut in the dimensions of $2 \times 2 \mathrm{~cm}^{2}$. These coupons were then degreased by emery papers of grade numbers 100 to 600 . The coupons were mechanically cleaned followed by cleaning with emery sheet of fine quality to uncover sparkling cleaned surface. To evacuate any oil and organic impurities coupons were degreased with acetone and with de-ionized water, dried and put away in desiccators. Exact weight of the samples was taken utilizing electronic balance. After immersion of these coupons in acid solutions, these were washed with saturated solution of sodium bicarbonate and then acetone and were weighed gain. The weight loss was calculated using the formula [21-23]:

$\eta \%=\frac{W_{0}-W_{i}}{W_{0}} \times 100$

$\eta \%$ represents the inhibition efficiency; $\mathrm{W}_{0}$ and $\mathrm{W}_{\mathrm{i}}$ represent the initial and final weight respectively. The corrosion rate was also obtained by using the below formula:

$C r=\frac{87.6 w}{\text { A.t.D }}$

where, Cr represents the corrosion rate, $\mathrm{w}$ is the total weight loss, $\mathrm{A}$ is the area of specimen, $\mathrm{t}$ is the time and $\mathrm{D}$ is the density of metal. 


\section{Quantum chemical analysis}

In order to correlate the inhibition efficiency with the molecular properties of inhibitor, quantum chemical analysis was done which gives us information about the molecular structure and reactivity of inhibitor. Quantum chemical analysis was performed using the MNDO and AM1 method of the quantum chemical package MOPAC 6.0 of Hyperchem 7.5. Some of the important parameters determined include $\mathrm{E}_{\mathrm{HOMO}}, \mathrm{E}_{\mathrm{LUMO}}, \mathrm{E}_{\mathrm{LUMO}}-\mathrm{E}_{\mathrm{HOMO}}$, dipole moment $(\mu)$ and binding energy (BE). All these parameters have individual effect on the corrosion inhibition efficiency of inhibitor.

\section{Scanning electron microscopy}

For SEM analysis, the mild steel coupons were immersed in $100 \mathrm{~mL}$ of $1 \mathrm{M} \mathrm{HCl}$ in the presence and absence of optimum concentration of the two inhibitors, separately, for $1 \mathrm{~h}$. Then they were removed, rinsed quickly (with sodium bicarbonate, water and acetone) and dried. The surface morphology of the metal coupons was determined and recorded using scanning electron microscope.

\section{RESULTS AND DISCUSSION}

\section{Weight loss measurements}

Weight loss measurements were performed in order to find the corrosion inhibition efficiency of oregano on mild steel in acidic medium. The measurements were performed at different temperature and different concentrations of inhibitor. The variation of inhibition efficiency with the concentration of inhibitor was performed at $30{ }^{\circ} \mathrm{C}$ in $1 \mathrm{M}$ of $\mathrm{HCl}$ and it was seen that with increase in the concentration of inhibitor, the inhibition efficiency increases. This could due to increase in the components of inhibitor blocking the active site of metal from acidic attack and forming a protective layer [24]. Table 1 clearly shows the variation of inhibition efficiency at different concentrations of inhibitor.

Table 1. Calculated values of inhibition efficiency, corrosion rate and surface coverage with and without different concentrations of inhibitor at $30^{\circ} \mathrm{C}$.

\begin{tabular}{|c|c|c|c|}
\hline Concentration $(\mathrm{mg} / \mathrm{L})$ & $\eta \%$ & Corrosion rate & $\Theta$ \\
\hline Blank $(1 \mathrm{M})$ & & 95.3 & \\
\hline 400 & 59 & 39 & 0.59 \\
\hline 600 & 74 & 25.07 & 0.74 \\
\hline 800 & 82.45 & 16.7 & 0.82 \\
\hline 1000 & 91.22 & 8.35 & 0.91 \\
\hline 1200 & 93.38 & 6.24 & 0.93 \\
\hline
\end{tabular}

The variation of inhibition efficiency with concentration was studied and data showed that when we increase the concentration in presence of inhibitors, efficiency also increases and it is due to adsorption mechanism. It is also observed that with increase in temperature, inhibition efficiency decreases. This impact can be ascribed to the desorption of adsorbed inhibitor particles from the metal surface because of which more prominent surface area of metal interacted with the corrosive environment bringing about the expanded corrosion rates [25, 26].

The variation of inhibition efficiency with temperature is studied and it was clear that while increasing the temperature from 298 to $313 \mathrm{~K}$ efficiency decreases temperature. As the temperature increases, inhibition efficiency decreases and corrosion rate increases. From weight loss technique the good efficiency was obtain at $30{ }^{\circ} \mathrm{C}$ due to decrease in the adsorption of inhibitor molecules. 
Thermodynamic parameters are important to understand the mechanism of adsorption. The different values of different thermodynamic parameters give us ideas about mode of adsorption and spontaneity of a reaction. Arrhenius equation was used to know the activation energy:

$C_{r}=A \exp \left(\frac{-E_{a}}{R T}\right)$

where $\mathrm{C}_{\mathrm{r}}$ is the corrosion rate (\%), $\mathrm{E}_{\mathrm{a}}$ is the activation energy $(\mathrm{J}), \mathrm{R}$ is the gas constant $\left(\mathrm{J} \cdot \mathrm{mol}^{-1}\right.$. $\mathrm{K}^{-1}$ ) and $\mathrm{T}$ is the temperature $(\mathrm{K})$. Figure 2 represents the Arrhenius plot of with blank $\mathrm{HCl}$ and inhibitor.

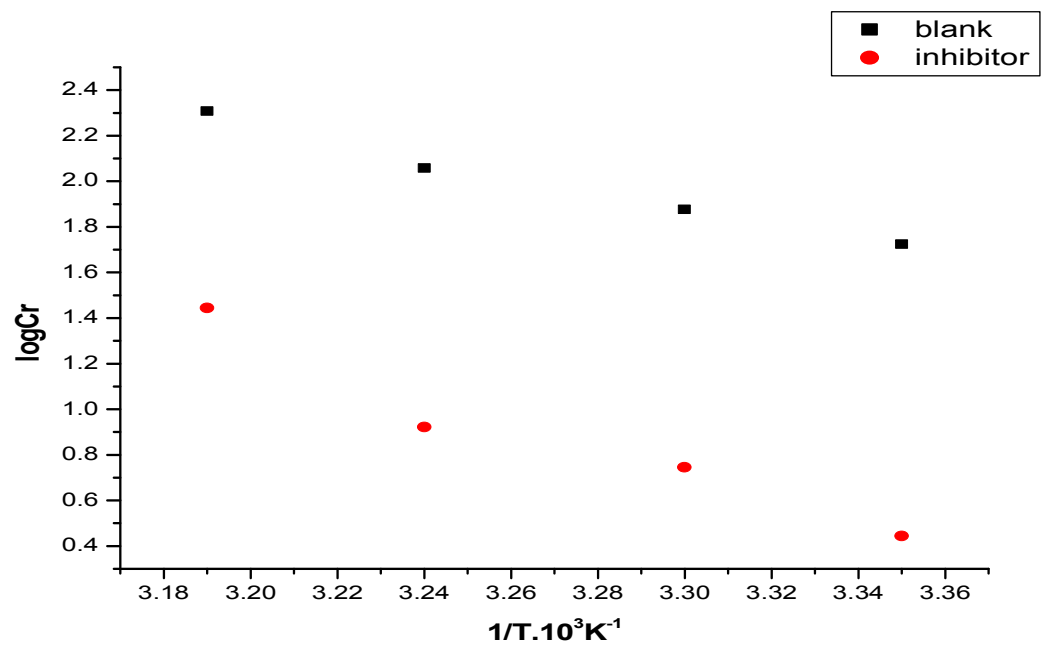

Figure 2. Arrhenius plot of blank $1 \mathrm{M}$ of $\mathrm{HCl}$ and inhibitor.

It is evident from the plot above that activation energy of blank $\mathrm{HCl}$ is lesser than that of inhibitor, this can be attributed to the fact that physical barrier formed as a result of adsorption of inhibitor molecules on the surface of mild steel [28, 29]. The enthalpy of activation was calculated by using Eyring equation:

$\ln \frac{C_{r}}{T}=\left(-\frac{\Delta H}{R}\right) \cdot \frac{1}{T}+\left(\frac{\ln R}{N h}+\frac{\Delta S}{R}\right)$

where, $\mathrm{h}$ is the planks constant (J.s), $\mathrm{N}$ is the Avogadro's number; $\Delta \mathrm{H}$ is the enthalpy of activation $(\mathrm{KJ} / \mathrm{mol})$ and $\Delta \mathrm{S}$ is the entropy of activation $(\mathrm{J} / \mathrm{K})$. The Eyring plot between $\log \mathrm{C}_{\mathrm{R}} / \mathrm{T}$ vs. $1000 / T$ gave a straight line with slope equal to $-\Delta H / R$, from the values of this slope, the values of $\Delta \mathrm{H}$ was elucidated.

Gibb's free energy is one of the most important factors in determining the spontaneity of reaction. The value of Gibb's free energy was calculated by using the below formula:

$\Delta G_{\text {ads }}^{\circ}=-2.303 R T \log \left(55.5 K_{\text {ads }}\right)$

The molar concentration of water I a solution is 55.5 mol. $\mathrm{L}^{-1}[22]$. The values of $\Delta G_{\text {ads }}^{\circ}, \Delta \mathrm{H}_{\text {ads }}^{\circ}$ were used to determine the values of entropy of activation from the below equation:

Bull. Chem. Soc. Ethiop. 2019, 33(1) 
Investigation on mitigation of corrosion of mildsteel by Origanum vulgare in acidic medium 163

$\Delta G_{\text {ads }}^{\circ}=\Delta H_{\text {ads }}^{\circ}-T \Delta S_{\text {ads }}^{\circ}$

All the calculated values of thermodynamic parameters are given in Table 2. The mode of adsorption is spontaneous and indicates physical adsorption as indicated by the negative value of $\Delta \mathrm{G}_{\text {ads }}^{\circ}$ [30]. The endothermic nature of adsorption was elucidated by the positive value of $\Delta \mathrm{H}_{\text {ads }}^{\circ}$

Higher value of $\Delta \mathrm{H}_{\text {ads }}^{\circ}$ in presence of inhibitor than blank indicates the metal dissolution is less due to the formation of protective layer of inhibitor on metal surface [31]. Positive value of $\Delta \mathrm{S}$ is an indication that system disordering increases due to the formation of protective layer.

Table 2. Calculated values of thermodynamic parameters for a solution containing $1 \mathrm{M}$ of $\mathrm{HCl}$ and 1000 $\mathrm{mg} / \mathrm{L}$ of inhibitor.

\begin{tabular}{|c|c|c|c|c|}
\hline Inhibitor & $\mathrm{E}_{\mathrm{a}}\left(\mathrm{kJ} . \mathrm{mol}^{-1}\right)$ & $\Delta \mathrm{H}\left(\mathrm{kJ}^{-1} \mathrm{~mol}^{-1}\right)$ & $\Delta \mathrm{G}_{\text {ads }}\left(\mathrm{kJ} \cdot \mathrm{mol}^{-1}\right)$ & $\Delta \mathrm{S}^{\mathrm{o}}\left(\mathrm{J} . \mathrm{mol}^{-1}\right)$ \\
\hline 1 M HCl (blank) & 68.46 & 28.60 & -5.502 & 112.5 \\
\hline Origanum vulgare & 111.9 & 47.47 & -12.05 & 196.4 \\
\hline
\end{tabular}

Adsorption isotherms play an important role in determining the mechanism of adsorption. Generally two adsorption isotherms are considered via Freundlich and Langmuir adsorption isotherm.

Langmuir isotherm; $\frac{\theta}{1-\theta}=K_{a d s} C$

Freundlich isotherm; $\theta=K_{a d s} C$

where, $\mathrm{C}$ is the concentration of inhibitor, $\mathrm{K}_{\mathrm{ads}}$ is the equilibrium constant and $\Theta$ is the surface coverage. Figure 3 shows the plot of $\log \mathrm{C} / \Theta$ vs. $\log \mathrm{C}$ gave a straight line with slope almost equal to 1 , indicating that the best linear fit of adsorption obeys Langmuir adsorption isotherm [31].

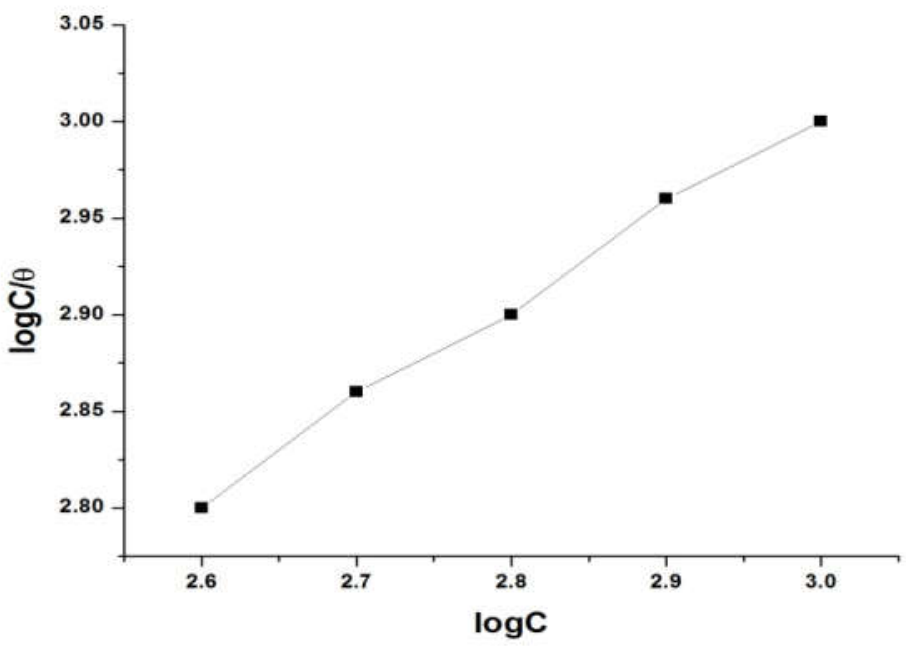

Figure 3. Langmuir adsorption isotherm plot for corrosion of mild steel in acidic medium. 
Quantum chemical study

The molecular properties and reactivity of inhibitor was studied by using quantum chemical techniques. Some of the important parameters estimated include $\mathrm{E}_{\mathrm{HOMO}}, \mathrm{E}_{\mathrm{LUMO}}, \mathrm{E}_{\mathrm{LUMO}}-\mathrm{E}_{\mathrm{HOMO}}$, dipole moment, etc. Figures 4, $5(\mathrm{a}, \mathrm{b})$ indicate the HOMO and LUMO of carvacrol and thymol, respectively. The molecular structure of carvacrol and thymol shows that the molecules seems to adsorb on steel surface by sharing of electrons of the nitrogen and oxygen atoms with iron to form coordinated bonds and $\pi$-electron interactions of the aromatic rings.
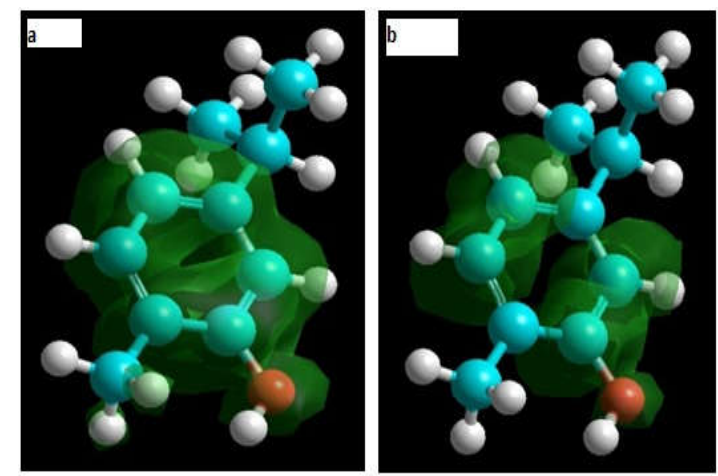

Figure 4. (a) HOMO of carvacrol and (b) LUMO of carvacrol.
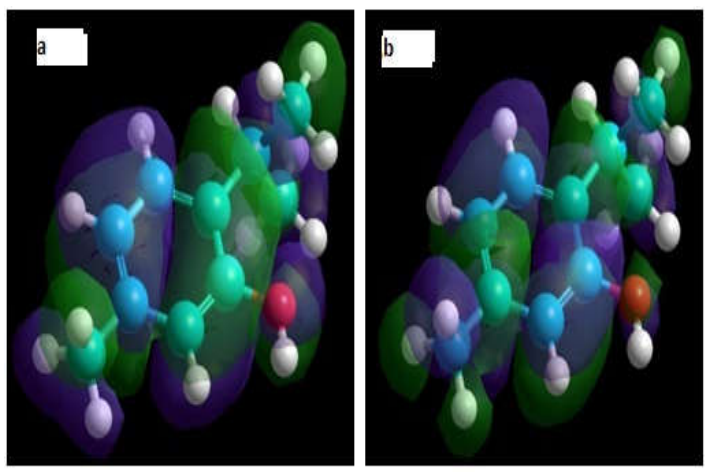

Figure5. (a) HOMO of thymol and (b) LUMO of thymol.

The negative value of binding energy suggests stability of the protective layer formed. The negative value of heat of formation indicates that the formation of activated complex between metal surface and inhibitor is stable. From the higher value of dipole moment it is clear that the inhibition efficiency is higher because of the higher polarization. The inhibition efficiency varies directly with increasing values of $\mathrm{E}_{\text {HOMO }}$ and inversely with decreasing values of $\mathrm{E}_{\mathrm{LUMO}}$. Lower $\Delta \mathrm{E}$ values suggest better is the inhibition efficiency of the inhibitor. Table 3 gives the data of all the quantum chemical parameters of carvacrol and thymol [31]. 
Investigation on mitigation of corrosion of mildsteel by Origanum vulgare in acidic medium 165

Table 3. Quantum chemical parameters of oregano.

\begin{tabular}{|c|c|c|c|c|c|c|c|c|c|}
\hline & $\begin{array}{c}\text { Total energy } \\
\mathrm{kcal} / \mathrm{mol}\end{array}$ & $\begin{array}{c}\text { Binding } \\
\text { energy } \\
\mathrm{kcal} / \mathrm{mol}\end{array}$ & $\begin{array}{c}\text { Electronic } \\
\text { energy } \\
\mathrm{kcal} / \mathrm{mol}\end{array}$ & $\begin{array}{c}\text { Heat of } \\
\text { formation } \\
\mathrm{kcal} / \mathrm{mol}\end{array}$ & $\begin{array}{c}\text { Molecular } \\
\text { point } \\
\text { group }\end{array}$ & $\begin{array}{c}\text { Dipole } \\
\text { moment }\end{array}$ & $\begin{array}{c}\mathrm{E}_{\text {Homo }} \\
(\mathrm{eV})\end{array}$ & $\begin{array}{c}\mathrm{E}_{\text {LUMO }} \\
(\mathrm{eV})\end{array}$ & $\begin{array}{c}\Delta \mathrm{E} \\
\left(\mathrm{E}_{\text {LUMO- }}\right. \\
\mathrm{E}_{\text {Homo }} \\
(\mathrm{eV})\end{array}$ \\
\hline Thymol & -41505 & -2542 & -220319 & -44.31 & $\mathrm{C} 1$ & 1.225 & -8.835 & 0.2964 & 9.131 \\
\hline Carvacrol & -41506 & -2543 & -218066 & -45.58 & $\mathrm{C} 1$ & 1.075 & -8.849 & 0.0451 & 8.894 \\
\hline
\end{tabular}

Mechanism of adsorption

The mechanism of adsorption can be understood by the clarification of interaction between the inhibitor molecules and metal surface. In $\mathrm{HCl}$, with respect to potential zero charge, steel is positively charged. Figure 6 shows that inhibitor may adsorb on the metal/acid solution interface by the following ways: (i) donor-acceptor interactions between the p-electrons of aromatic ring and vacant p-orbitals of surface mildsteel atoms and (ii) interaction between unshared pair of heteroatoms and vacant d-orbitals of surface mild steel atoms [32].

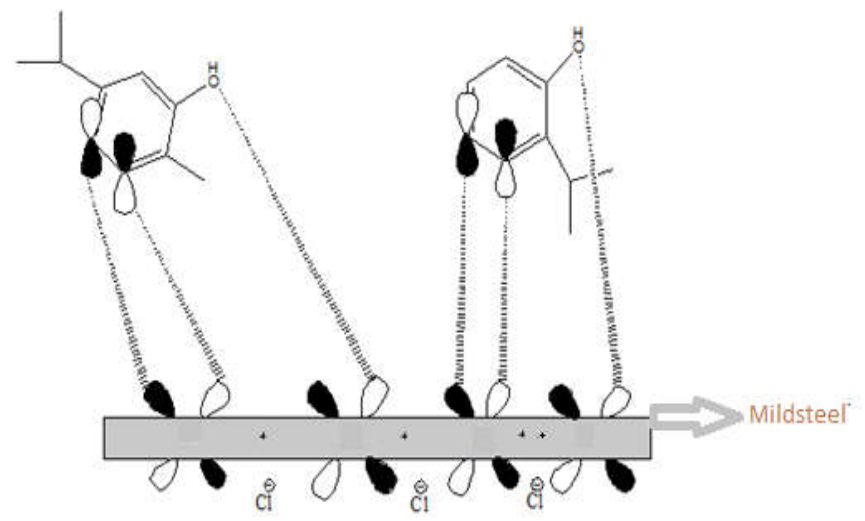

Figure 6. Representing interaction between the inhibitor molecules and metal surface.

\section{Scanning electron microscopy}

The surface analysis of mild steel immersed in $\mathrm{HCl}$ and inhibitor was done. It is clear from the (Figure 7a, b, c) showing the SEM micrographs of polished mild steel, mild steel immersed in $\mathrm{HCl}$ and mild steel immersed in inhibitor solution that (b) has rough surface with cavities and pores whereas (c) has lesser cavities and less rough surface. Thus, it can be thought of an evidence of adsorption of inhibitor on the surface of mild steel [33, 34]. 


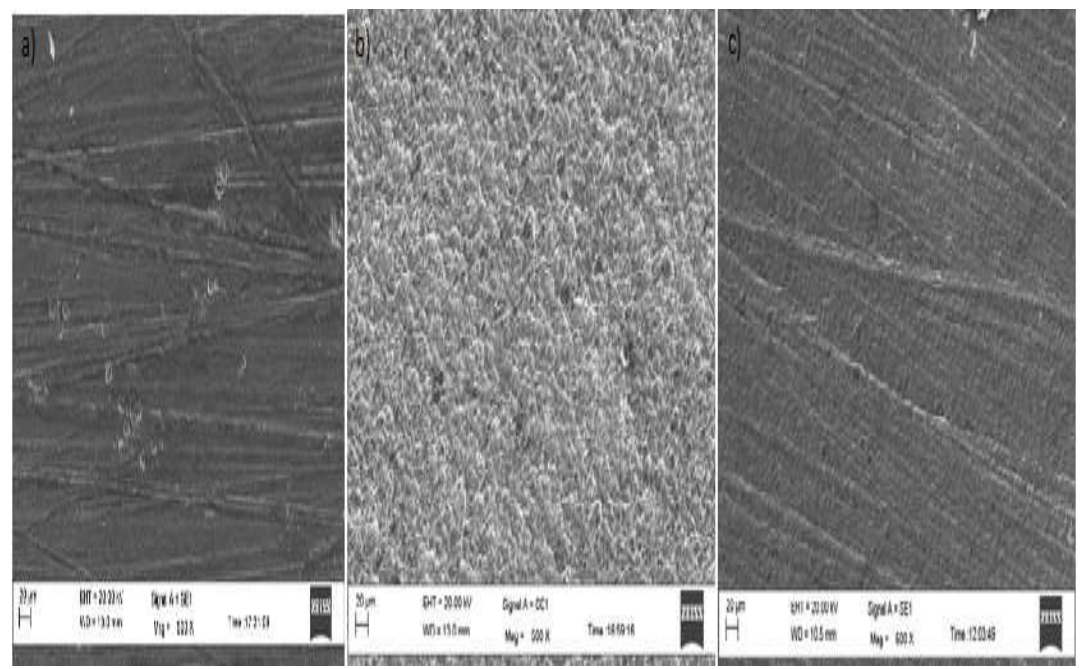

Figure 7. (a) Polished mild steel, (b) mild steel with $1 \mathrm{M} \mathrm{HCl}$ and (c) mild steel with oregano extract in $1 \mathrm{M}$ of $\mathrm{HCl}$.

\section{CONCLUSION}

The studied inhibitor showed efficient inhibition properties for corrosion of mild steel in $1 \mathrm{M}$ $\mathrm{HCl}$ and its inhibition efficiency increased with the increase in the concentration. At $1000 \mathrm{mg} / \mathrm{L}$ concentration of inhibitor, $91.2 \%$ inhibition efficiency was recorded. The positive values of $\Delta \mathrm{H}$ were obtained which indicated adsorption process was endothermic in nature. Adsorption of these compounds on mild steel surface has been found to obey Langmuir adsorption isotherm. The results obtained from weight loss measurements, scanning electron microscopy images and quantum chemical calculations were in reasonable agreement.

\section{REFERNCES}

1. Ulaeto, S.B.; Ekpel, U.J.; Chidiebere, M.A.; Oguzie, E.E. Corrosion inhibition of mild steel in hydrochloric acid by acid extracts of Eichhornia crassipes. Int. J. Mater. Chem. 2012, 2 , $158-164$.

2. Verma, C.; Quraishi M.A.; Ebenso E.E.; Bahadur I. A green and sustainable approach for mild steel acidic corrosion inhibition using leaves extract: Experimental and DFT studies. $J$. Bio-and Tribo-Corrosion 2018, 4, 33-45.

3. Yousefi, A.; Aslanzadeh, S.A.; Akbari, J. Experimental and DFT studies of 1methylimidazolium trinitrophenoxide as modifier for corrosion inhibition of SDS for mild steel in hydrochloric acid. Anti-Corros. Method. Mater. 2018, 65, 107-122.

4. Singh, A.; Ansari, K.R.; Haque, J.; Dohare, P.; Lgaz, H.; Salghi, R.; Quraishi, M.A. Effect of electron donating functional groups on corrosion inhibition of mild steel in hydrochloric acid: Experimental and quantum chemical study. J. Taiwan Inst. Chem. Eng. 2018, 82, 233251.

5. Okafor, P.C.; Ebenso, E.E.; Ekpe, U.J. Inhibition of the acid corrosion of aluminium by some derivatives of thiosemicarbazone. Bull. Chem. Soc. Ethiop. 2004, 18, 181-192. 
6. Shanmugapriya, S.; Prabhakar, P.; Rajendran, S. Corrosion resistance property of mild steel in simulated concrete pore solution prepared in well water by using an aqueous extract of turmeric. Mater. Today: Proceedings 2018, 5, 8789-8795.

7. Valek, L.; Martinez, S. Copper corrosion inhibition by Azadirachta Indica leaves extract in sulfuric acid. Mater. Lett. 2007, 61, 148-151.

8. Abdallah, M.; Altass, H.M.; Al-Jahdaly, B.A.; Salem, M.M. Some natural aqueous extracts of plants as green inhibitor for carbon steel corrosion in $0.5 \mathrm{M}$ sulfuric acid. Green Chem. Lett. Rev. 2018, 11, 189-196.

9. Raghavendra, N.; Bhat, J.I. An environmentally friendly approach towards mitigation of al corrosion in hydrochloric acid by yellow colour ripe arecanut husk extract: Introducing potential and sustainable inhibitor for material protection.J. Bio-and Tribo-Corrosion 2018, 4, 2. DOI: 10.1007/s40735-017-0112-1.

10. Gece, G. Revealing the inhibition efficiencies of artesunate and rutin for corrosion of steel: A theoretical study. Key Eng. Mater. 2018, 762, 325-329.

11. Bashir, S.; Singh, G.; Kumar, A. An investigation on mitigation of corrosion of aluminium by Origanum vulgare in acidic medium. Prot. Met. Phys. Chem. Surf. 2018, 54, 148-152.

12. Battistin, A. Alcoholic extract mint is used as a low carbon steel corrosion inhibitor in aqueous medium. J. Solid State Electrochem. 2012, 16, 747-752.

13. Abiola, O.K.; Odin, E.M.; Olowoyo, D.N.; Adeloye, T.A. Gossipium hirsutum L. extract as green corrosion inhibitor for aluminum in $\mathrm{HCl}$ solution. Bull. Chem. Soc. Ethiop. 2011, 25, 475-480.

14. Znini, M.; Bouklah M.; Majidi, L.; Aouniti. A.; Bouyanze, A.; Hammouti, B. Chemical composition and inhibitory effect of Mentha spicata essential oil on the corrosion of steel in molar hydrochloric acid. Int. J. Electrochem. Sci. 2011, 6, 691-704.

15. Umoren, S.A. Biomaterials for corrosion protection: evaluation of mustard seed extract as eco-friendly corrosion inhibitor for X60 steel in acid media. J. Adhesion Sci. Technol. 2016, 30, 1858-1879.

16. Boumhara, K.; Bentiss, F.; Tabyaoui, M.; Hammouti, B. Use of Artemisia Mesatlantica Essential Oil as Green Corrosion Inhibitor for Mild Steel in $1 \mathrm{M}$ Hydrochloric Acid Solution. Int. J. Electrochem. Sci.2014, 9, 1187-1206.

17. Quraishi, M.A.; Jamal, D. Dianils as New and Effective Corrosion Inhibitors for Mild steel in Acidic Solutions. Materials Chemistry and Physics 2003, 78,608.

18. Singh, A.; Lin, Y. Berberine as an Effective Corrosion Inhibitor for 7075 Aluminium Alloy in 3.5\% NaCl Solution. Int.J.Electrochem. Sci.2014, 9, 5585

19. Singh, A.; Lin, Y.; Ebenso, E.E.; Liu, W.; Kuanhai, D.; Pan, J.; Bo Huang, B. Relevance of electrochemical and surface studies to probe Zanthoxylum schinifolium (sichuan pepper) as an effective corrosion inhibitor for $\mathrm{N} 80$ steel in $\mathrm{CO}_{2}$ saturated $3.5 \% \mathrm{NaCl}$ solution. Int. J. Electrochem. Sci. 2014, 9, 5585-5595.

20. Sheikhshoaie, I.; Nezamabadipour, H. Theoretical study on the structural effect of some organic compounds as corrosion inhibitors on mild steel in acid media. Bull. Chem. Soc. Ethiop. 2009, 23, 309-313.

21. Abboud, A.; Abourriche, A.; Ainane, T.; Charrouf, M.; Bennamara, A.; Tanane, O.; Hammouti, B. Corrosion inhibition of carbon steel in acidic media by Bifurcaria bifurcate extract. Chem. Eng. Comm. 2009, 196, 788-800.

22. Ita, B.I. Inhibition of the corrosion of mild steel in hydrochloric acid by isatin and isatin glycine. Bull. Chem. Soc. Ethiop. 2006, 20, 253-258

23. Sorkhabi H.K.; Haghi M.E. Corrosion inhibition of mild steel in hydrochloric acid by betanin as a green inhibitor. J. Solid State Electrochem. 2009, 13, 1297-1301.

24. Ansari, K.R.; Quraishi, M.A. Isatin derivatives as a non-toxic corrosion inhibitor for mild steel in $20 \% \mathrm{H}_{2} \mathrm{SO}_{4}$. Corros. Sci. 2015, 95, 62-70. 
25. Alkhathlan, H.Z.; Khan, M. Launaea nudicaulis as a source of new and efficient green corrosion inhibitor for mild steel in acidic medium: A comparative study of two solvent extracts. Int. J. Electrochem. Sci. 2014, 9, 870-889.

26. Kumar, A.; Bashir, S. Ethambutol: A new and effective corrosion inhibitor of mild steel in acidic medium. Russ. J. Appl. Chem. 2016, 89, 1158-1163.

27. Ahamad, I.; Prasad, R.; Quraishi, M.A. Thermodynamic, electrochemical and quantum chemical investigation of some Schiff bases as corrosion inhibitors for mild steel in hydrochloric acid solutions. Corros. Sci. 2010, 52, 933-942.

28. Okafor, P.C.; Ikpia, M.E.; Uwaha, I.E.; Ebenso, E.E.; Umoren, S.A. Inhibitory action of Phyllanthus amarus extracts on the corrosion of mild steel in acidic medium. Corros. Sci. 2008, 50, 2310-2317.

29. Bashir, S.; Sharma, V.; Lgaz, H.; Chung, I.M.; Singh, A.; Kumar, A. The inhibition action of analgin on the corrosion of mild steel in acidic medium: A combined theoretical and experimental approach. J. Mol. Liq. 2018, 263, 454-462.

30. Bashir, S.; Singh, G.; Kumar, A. Shatavari (Asparagus Racemosus) as green corrosion inhibitor of aluminium in acidic medium. J. Mater. Environ. Sci. 2017, 8, 4284-4291.

31. Helen, L.Y.S.; Rahim, A.A.; Saad, B.; Saleh, M.I. Aquilaria crassna leaves extracts - A green corrosion inhibitor for mild steel in $1 \mathrm{M} \mathrm{HCl}$ medium. Int. J. Electrochem. Sci. 2014, 9, 830-846.

32. Singh, A.; Gupta, A.; Rawat, A.K.; Ansari, K.R.; Quraishi, M.A. Cimetidine as an effective corrosion inhibitor for mild steel in hydrochloric acid. Int. J. Electrochem. Sci. 2014, 9, 7614-7628.

33. Orguzie, E.E.; Corrosion inhibitive effect and adsorption behaviour of Hibiscus sabdariffa extract on mild steel in acidic media. Portugal. Electrochim. Acta 2008, 26, 303-314.

34. El-Haddad, M.N. Chitosan as a green inhibitor for copper corrosion in acidic medium. Int. J. Biol. Macromolecules 2013, 55, 142-149. 